\title{
IMPACT OF VASCULAR RISK FACTORS ON COGNITIVE DECLINE ASSOCIATED WITH DIABETES MELLITUS
}

\author{
Mirena P. VALKOVA ${ }^{1,2} \bowtie$, Ivanka I. VELEVA ${ }^{3}$, Velina N. GUERGUELTCHEVA ${ }^{1}$, \\ Presian S. BURGOV ${ }^{2}$ \\ ${ }^{1}$ Clinic of Neurology, University Hospital „Sofiamed“, Sofia, Bulgaria \\ 2 Psychological department, Philosophic Faculty, The University of Veliko Tarnovo „St. Kiril et Metodi“, \\ Veliko Tarnovo, Bulgaria \\ ${ }^{3}$ Department of Psychiatry and Medical psychology, Medical University Pleven, Pleven, Bulgaria
}

Received 20 Jun 2019, Accepted 04 August 2019

https://doi.org/10.31688/ABMU.2019.54.3.14

\begin{abstract}
Introduction. Vascular risk factors have been associated with cognitive decline, although their simultaneous effects on cognition are unclear.

The aim of our study was to examine the additional impact of some of the most important risk factors (ageing, arterial hypertension $(\mathrm{AH})$, chronic ischemic heart disease (CIHD), tobacco-usage and alcohol) on cognitive functions of patients with diabetes mellitus (DM). Material and methods. We examined 115 patients (average age $62.47 \pm 10.60$ years; 49 males, 66 females) with DM (mean disease duration $9.28 \pm 6.88$ years), admitted between 2016-2017 in the Neurology Clinic of the University Hospital „Sofiamed“, Sofia, Bulgaria. We used the following neuropsychological battery: Mini Mental State Examination (MMSE), Isaack Set Test, 10 words memory test, Digit Symbol Substitution Test, Trail Making Test A and B, Clock drawing test, Logic memory test (subscale of Wechsler memory scale IV ed.), Benton visual retention test (var. A, form E). The results were summarized in tables. All the results were analyzed in 95\% confidence interval.
\end{abstract}

Results. Ageing was associated with a poor cognitive performance in almost all examined cognitive

\section{Résumé}

L'impact de différents facteurs de risque vasculaires sur le déclin cognitif associés au diabète sucré

Introduction. Les facteurs de risque vasculaire sont associés au déclin cognitif, bien que leurs effets simultanés sur la cognition ne soient pas clairs.

Le but de notre étude était d'étudier l'impact supplémentaire de certains des facteurs de risque les plus importants (vieillissement, hypertension artérielle (HA), cardiopathie ischémique chronique (CIC), consommation de tabac et d'alcool sur la fonction cognitive des patients atteints de diabète sucré.

Matériels et méthodes. Nous avons étudié 115 patients atteints de diabète sucré (âge moyen: 62,47士10,60 ans, 49 hommes, 66 femmes, durée moyenne de la maladie: 9,28 $\pm 6,8$ ans), hospitalisés entre 2016-2017 à la clinique de neurologie de l'hôpital universitaire Sofiamed de Sofia. Nous avons utilisé la batterie neuropsychologique suivante: mini-examen de l'état mental (MMSE), test d'Isaack Set, test d'apprentissage de 10 mots, test de substitution du symbole des chiffres, test de détermination du parcours $\mathrm{A}$ et $\mathrm{B}$, Clock drawing test et test de Benton (var. A, formulaire E). 
domains, except MMSE. CIHD is associated with low Digit Symbol Substitution Test points and more omissions and size errors on Benton Visual Retention Test. Conclusions. Ageing is associated with decline in visual and verbal memory, executive functions and visual-spatial abilities in cases with DM. CIHD leads to additional alternating attention deficits in patients with DM. AH, tobacco-usage and mild and moderate alcohol drinking are not significantly associated with additional cognitive dysfunctions in cases with DM.

Keywords: vascular risk factors, cognitive decline, diabetes mellitus, arterial hypertension.
Les résultats sont résumés dans les tableaux. Tous les résultats sont analysés à un intervalle de confiance de $95 \%$.

Résultats. Le vieillissement est associé à des performances médiocres dans presque tous les domaines cognitifs examinés, à l'exception du MMSE. Le CIC est associé à un nombre réduit de points DSST et à davantage d'erreurs de type et de taille dans le test de rétention optique de Benton.

Conclusions. Le vieillissement du diabète sucré est associé à une diminution de la mémoire visuelle et verbale, des fonctions exécutives et des capacités visuelles et spatiales. CIC chez les patients atteints de diabète sucré provoque des déficits d'attention supplémentaires. $\mathrm{HA}$, le tabagisme et la consommation d'alcool léger à modéré ne sont pas associés de manière significative à des dysfonctionnements cognitifs supplémentaires.

Mots-clés: facteurs de risque vasculaire, déclin cognitif, diabète sucré, hypertension artérielle.

oxidative stress and atherosclerosis and increased risk for vascular brain disease ${ }^{10}$.

The association between alcohol and cognitive functions is non-linear and depends on the alcohol quantity (the small amounts can have positive effect) and individual age ${ }^{11-13}$. It is associated with chronic somatic and brain diseases, developed by 2 main mechanisms - the impact of chronic use of ethanol itself (direct intoxication or alcohol dependence) and loss of thiamine ${ }^{14}$.

Many patients with DM have additional vascular risk factors, particularly those with metabolic syndrome. However, the relations between DM and other vascular risk factors on cognition remain unclear.

THE AIM OF OUR STUDY was to examine the additional impact of some of the most important risk factors (ageing, $\mathrm{AH}, \mathrm{CIHD}$, tobacco-usage and alcohol) on cognitive functions of patients with DM.

\section{Material AND MEthods}

We examined 115 patients (mean age $62.47 \pm 10.60$ years; 49 males, 66 females) with DM (13 with DM type 1 and 102 with type 2; mean duration of disease 9.28 \pm 6.88 years), admitted between 2016-2017 in the Neurology Clinic of the University Hospital „Sofiamed“, Sofia, Bulgaria. The inclusion criteria in the study were:

1. Patients with DM with duration of more than 1 year on stable treatment and without severe hypoglycemic or hypoglycemic episodes during the last 2 weeks. 2. Over 18 years of age and formal education $>8$ years. 
3. Lack of family history of dementia, brain disease (except multi-infarct encephalopathy or cortical atrophy due to DM) or psychiatric diseases.

4. Ability to fulfill our neurological battery.

5. Signed informed consent.

6. Lack of any diagnostic uncertainties, aphasia, apraxia or agnosia, moderate or severe decompensation of somatic diseases, history of taking prohibited substances or alcohol dependence or history of taking drugs which could lead to cognitive or psychic changes.

All hypertensive patients should have the diagnosis of $\mathrm{AH}$ with a duration of more than 2 years, on stable treatment.

All patients with CIHD should fulfill the criteria of American College of Cardiology and American Heart Association (2012) with duration of the disease $>2$ years and should be on stable treatment.

All patients with alcohol drinking should take no more than 100 alcohol units/week.
The patients were divided into the following groups: with $\mathrm{AH}(\mathrm{n}=64)$ and without $\mathrm{AH}(\mathrm{n}=51)$; with $\operatorname{CIHD}(\mathrm{n}=32)$ and without $\mathrm{CIHD}(\mathrm{n}=83)$; former smokers $(n=25)$, current smokers $(n=24)$, no-smokers $(\mathrm{n}=66)$; alcohol-drinkers $(\mathrm{n}=38)$ and abstainers $(\mathrm{n}=77)$.

We used the following neuropsychological battery: Mini Mental State Examination (MMSE), Isaack Set Test, 10 words memory test, Digit Symbol Substitution Test, Trail Making Test A and B, Clock drawing test, Logic memory test (subscale of Wechsler memory scale IV ed.), Benton visual retention test (var. A, form E).

After signing the informed consent, all patients were screened by history data, blood and urine examinations, full somatic and neurological examinations and brain computed tomography. The patients who were eligible for the study, were examined by neurological battery given above.

Statistical analysis was done via parametric and nonparametric methods, regression and correlation analysis, using Microsoft Excel 2010, Statgraphics

Table 1. The impact of ageing on cognitive functions of patients with Diabetes Mellitus.

\begin{tabular}{|c|c|c|}
\hline & $\mathrm{p}=$ & $\mathrm{rr}=$ \\
\hline MMSEp. & $\mathrm{p}>0.05$ & $\ldots$ \\
\hline Working memory & $\mathrm{p}=0.0001$ & -0.43 \\
\hline Yfix* & $\mathrm{p}=0.0001$ & -0.43 \\
\hline Yrep* & $\mathrm{p}=0.0101$ & -0.24 \\
\hline Yret $^{*}$ & $\mathrm{p}>0.05$ & $\ldots$ \\
\hline Delayed recall (words) & $\mathrm{p}=0.0001$ & -0.37 \\
\hline DSSTp. & $\mathrm{p}=0.0001$ & -0.44 \\
\hline CDTp. & $\mathrm{p}>0.05$ & $\ldots$ \\
\hline Logic memory A (number of items) & $\mathrm{p}=0.0021$ & -0.28 \\
\hline Logic memory B (number of items). & $\mathrm{p}>0.05$ & $\ldots$ \\
\hline Logic memory total number of items & $\mathrm{p}=0.0402$ & -0.19 \\
\hline $\mathrm{VF}^{*} \mathrm{p}$ & $\mathrm{p}=0.0482$ & -0.18 \\
\hline TMTAsec & $\mathrm{p}=0.0001$ & +0.51 \\
\hline TMTB*sec $^{*}$ & $\mathrm{p}=0.0001$ & +0.47 \\
\hline BVRT corrects & $p=0.0343$ & -0.20 \\
\hline BVRT errors & $\mathrm{p}=0.0128$ & +0.23 \\
\hline Omissions* & $\mathrm{p}>0.05$ & $\ldots$ \\
\hline Distortions & $p=0.0272$ & +0.21 \\
\hline Perseverations ${ }^{*}$ & $\mathrm{p}=0.0002$ & +0.42 \\
\hline Rotations & $p>0.05$ & $\ldots$ \\
\hline Misplacement errors* & $p>0.05$ & $\ldots$ \\
\hline Size errors* & $\mathrm{p}>0.05$ & $\ldots$ \\
\hline
\end{tabular}

MMSE Mini Mental State Examination; Working memory - average result after five attempts on 10 words memory test. Y fix - fixation coefficient in \%, Y rep - reproduction coefficient in \% Y ret - retention coefficient in \%, DSST - Digit Symbol Substitution Test $(90 \mathrm{sec})$; CDT Clock Drawing Test, VF - verbal fluency (Isaac's Set Test), TMT - Trial Making Test, BVRT - Benton visual retention test

${ }^{*}$ The results were done after transformation of data with log and after excluding other suitable models outside linear. All results were interpreted after statistical elimination of the factor duration of DM. 
Plus 5.0 and SPSS 20 including ANOVA, Pearson, Mann-Whitney, t-test, Fisher test, lambda test and Kruskall-Wallis statistics. The results were summarized in tables. All results were analyzed in 95\% confidence interval.

\section{Results}

The impact of ageing on cognitive functions of patients with DM: ageing is associated with cognitive decline (see Table 1).

The impact of $\mathrm{AH}$ on cognitive functions of patients with DM: we failed to find any additional impact of $\mathrm{AH}$ on examined cognitive parameters of our patients $(\mathrm{p}>0.05)$.

The impact of CIHD on cognitive functions of patients with DM: patients with CIHD had poorer performance on Digit Symbol Substitution Test than those without (average $25.71 \pm 11.72 \mathrm{p}$. vs $30.51 \pm 13.03 p$.; $p=0.0438)$. They also showed a lower number of correct items on BVRT (Med 3 vs Med 4; $\mathrm{p}=0.0188)$ and more omission errors (Med 2 vs Med $1, \mathrm{p}=0.0333$ ), as well as more size errors (Med 1 vs Med 0; $p=0.0456$ ) than patients without CIHD.

The impact of tobacco-usage on cognitive parameters of patients with DM: there were no statistically significant differences of cognitive functions $(p>0.05)$.

The impact of alcohol on cognitive functions of patients with DM: there were no statistically significant differences in cognition between abstainers and drinkers $(\mathrm{p}>0.05)$.

\section{Discussion}

DM and other vascular risk factors are in complex relations with respect to cognitive functions, but according to our study only some of them have additional impact on cognitive changes due to DM.

The most significant risk factor for additional cognitive decline in patients with DM seems to be ageing. It affects almost all examined cognitive domains, although we have failed to find correlations with global cognitive function measured by MMSE. Unlike us, Alencar and al (2010) have showed age-related MMSE decline in patients with DM, but without correction for DM duration ${ }^{15}$. We suggest that DM modifies the ageing effect on MMSE. Memory domain is significantly affected by ageing. Our analysis reveals that working memory, delayed recall and memory fixation of patients with DM decline with age, but not the ability for retention. The reproduction of verbal information also shows decrease over ageing. Such memory deficits can be associated with significant neuroplasticity changes ${ }^{16}$, development of more significant hypocampal atrophy ${ }^{1}$ or disconnection between important memory-associated brain regions ${ }^{17}$. The decreasing of executive functions with age is also well-known fact ${ }^{18,19}$. According to Fjell and al (2017), it is due to disconnection between different brain regions as a result of micro and macrovascular brain changes ${ }^{18}$. Our data show age-related decline in almost all basic executive domains - cognitive inhibition, attention, working memory and speed of information processing. According to Valencia and Florez (2017) the microvascular brain changes develop early in patients with DM, so their prevention has to be the key-stone for cognitive treatment ${ }^{19}$. One interesting question is whether the executive decline can cause itself microvascular damage, via neurotransmission changes between frontal lobe and hypothalamic-pituitary-adrenal axis and specific chronic stress reaction ${ }^{20}$. The question of pathological circus between executive dysfunction/neurodegeneration and microvascular changes remain unclear and have to be studied in future. However, ageing and DM are risk factors for frontal-hypothalamic disconnection and their simultaneous effect causes executive dysfunctions. Visual-spatial abilities also show a decline over time. Chena et al (2002) have suggested age-related de-differentiation which leads to changes of neuronal circuits responsible for visual-spatial abilities $^{21}$. On the other hand, de Bruin and al (2016) have pointed on selectively preservation of these functions in normal ageing ${ }^{22}$. Pal and al (2016) have shown that visual-spatial skills decline in cases with Alzheimer's disease and vascular brain disease, although the most impaired are object and spatial perceptions and the decline depends on the duration of both diseases ${ }^{23}$. Our analysis shows age-related increasing of perseverating errors and distortions and lack of increasing of so-called vertical errors (rotations, size errors and misplacement errors), which suggest age-related decreasing of non-verbal memory and visual perception. The age-related increasing of perseverations can be associated with frontal dysfunction (inability of cognitive inhibition) and shows dynamic frontal dysfunction due to simultaneous effects of DM and age.

$\mathrm{AH}$ has no additional effect on visual-spatial abilities, temporal and executive functions of patients with DM. However, Iadecola and al (2016) have pointed that DM and AH have their own additive, but not synergetic effect on cognitive functions ${ }^{3}$.

CIHD has additional effect on executive and visual-spatial decline in patients with DM. The mechanisms of its action are more complex that we have thought before and include not only vascular, but non-vascular brain damage. It causes more significant frontal and parietal but not temporal dysfunctions (executive and visual-spatial changes, but not memory problems) suggesting disconnections or functional 
changes at the level of important frontal-parietal networks. Moreover, we failed to find any significant differences on Trial making test or verbal fluency performances, but significant difference on Digit Symbol Substitution Test between patients with and without CIHD, which can be associated with poor horizontal and alternating attention, but not focused one. The alternating attention is strongly associated with simultaneous detection and perception of different objects. So, CIHD is an important risk factor for alternating attention deficit, especially in cases with DM.

We failed to find any cognitive differences between smokers and non-smokers and alcohol-drinkers and abstainers. However, we excluded all patients with alcohol dependence and with alcohol usage of more than 100 alcohol units/weekly. Cognitive functions of such kind of patients should be an object for future examinations.

\section{Conclusions}

Ageing is associated with decline in visual and verbal memory, executive functions and visual-spatial abilities in cases with DM. CIHD leads to additional alternating attention deficits in patients with DM. $\mathrm{AH}$, tobacco-usage and mild and moderate alcohol drinking are not significantly associated with additional cognitive dysfunctions in cases with DM.

\section{Compliance with Ethics Requirements:}

"The authors declare no conflict of interest regarding this article"

„The authors declare that all the procedures and experiments of this study respect the ethical standards in the Helsinki Declaration of 1975, as revised in 2008(5), as well as the national law. Informed consent was obtained from all the patients included in the study"

"No funding for this study"

\section{References}

1. Sadeghi A, Hami J, Razavi S, Esfandiary E, Hejazi Z. The effect of diabetes mellitus on apoptosis in hippocampus: cellular and molecular aspects. Int J Prev Med. 2016;7:57.

2. Stern Y. Cognitive reserve in ageing and Alzheimer's disease. Lancet Neurol. 2012; 11(11):1006-1012.

3. Iadecola C, Yaffe K, Biller J, et al. American Heart Association Council on Hypertension; Council on Clinical Cardiology; Council on Cardiovascular Disease in the Young; Council on Cardiovascular and Stroke Nursing; Council on Quality of Care and Outcomes Research; and Stroke Council. Impact of Hypertension on Cognitive Function: A Scientific Statement From the American Heart Association. Hypertension. 2016;68(6):e67-e94.
4. Grant H, Bhambhani Y, Singhal A. Hemodynamic changes in the prefrontal cortex during working memory in essential hypertension. J Am Soc Hypertens. 2015;9(8):628-39.

5. Faraco G, Sugiyama Y, Lane D, et al. Perivascular macrophages mediate the neurovascular and cognitive dysfunction associated with hypertension. J Clin Invest. 2016;126(12):4674-4689.

6. Tadic M, Cuspidi C, Hering D. Hypertension and cognitive dysfunction in elderly: blood pressure management for this global burden. BMC Cardiovasc Disord. 2016;16(1):208.

7. Sierra C, Salamero M, Domenech M, Camafort M, Coca A. Circadian blood pressure pattern and cognitive function in middle-aged essential hypertensive patients. Rev Esp Cardiol (Engl Ed). 2015;68(2):157-8.

8. Deckers K, Schievink SHJ, Rodriquez MMF, et al. Coronary heart disease and risk for cognitive impairment or dementia: Systematic review and meta-analysis. PLoS One. 2017;12(9):e0184244.

9. Gayda M, Gremeaux V, Bherer L, et al. Cognitive function in patients with stable coronary heart disease: Related cerebrovascular and cardiovascular responses. PLoS One. 2017;12(9):e0183791.

10. Swan GE, Lessov-Schlaggar CN. The effects of tobacco smoke and nicotine on cognition and the brain. Neuropsychol Rev. 2007;17(3):259-73.

11. Ilomaki J, Jokanovic N, Tan EC, Lonnroos E. Alcohol consumption, dementia and cognitive decline: an overview of systematic reviews. Curr Clin Pharmacol. 2015;10(3):204-12.

12. Gutwinski S, Schreiter S, Priller J, Henssler J, Wiers CE, Heinz A. Drink and think: impact of alcohol on cognitive functions and dementia - evidence of dose-related effects. Pharmacopsychiatry. 2018;51(4):136-143.

13. Piumatti G, Moore SC, Berridge DM, Sarkar C, Gallacher J. The relationship between alcohol use and long-term cognitive decline in middle and late life: a longitudinal analysis using UK Biobank. J Public Health (Oxf). 2018;40(2):304-311

14. Shield KD, Parry C, Rehm J. Chronic diseases and conditions related to alcohol use. Alcohol Res. 2013;35(2):155-73.

15. Alencar RC, Cobas RA, Gomes MB. Assessment of cognitive status in patients with type 2 diabetes through the Mini-Mental Status Examination: a cross-sectional study. Diabetol Metab Syndr. 2010;2:10.

16. Zheng Z, Wu J, Wang R, Zeng Y. Diabetes mellitus may induce cardiovascular disease by decreasing neuroplasticity. Funct Neurol. 2014;29(1):7-13

17. Sato N, Morishita R. Brain alterations and clinical symptoms of dementia in diabetes: $a \beta /$ tau-dependent and independent mechanisms. Front Endocrinol (Lausanne). 2014;5:143.

18. Fjell AM, Sneve MH, Grydeland H, Storsve AB, Walhovd $\mathrm{KB}$. The disconnected brain and executive function decline in aging. Cereb Cortex. 2017;27(3):2303-2317.

19. Valencia WM, Florez $\mathrm{H}$. How to prevent the microvascular complications of type 2 diabetes beyond glucose control. BMJ. 2017;356:i6505.

20. Madalena KM, Lerch JK. Glucocorticoids and nervous system plasticity. Neural Regen Res. 2016;11(1):37-41.

21. Chena J, Myerson J, Hale S. Age-related dedifferentiation of visuo-spatial abilities. Neuropsychologia. 2002;40:2050-6.

22. De Bruin N, Bryant DC, MacLean JN, Gonzalez CL. Assessing visuo-spatial abilities in healthy aging: a novel visuo-motor task. Front Aging Neurosci. 2016;1;8:7.

23. Pal A, Biswas A, Pandit A, Roy A, et al. Study of visuo-spatial skill in patients with dementia. Ann Indian Acad Neurol. 2016;19(1):83-8. 